\title{
E-visibility of environmental science researchers at the University of South Africa
}

\author{
Leslie Adriaanse ${ }^{1}$ and Chris Rensleigh ${ }^{2}$ \\ ladriaan@unisa.ac.za ORCID: orcid.org/0000-0001-5363-5059 \\ crensleigh@uj.ac.za ORCID: orcid.org/0000-0002-0577-4852
}

Received: 02 February 2017
Accepted: 20 January 2018

Research e-visibility embodies online presence on the World Wide Web, discoverability via research eprofiles and accessibility of research output available online. The purpose of this study is to report on the e-visibility status phase of a longitudinal e-visibility study (Dec 2014 - April 2017) investigating the e-visibility themes of online presence, researcher discoverability and accessibility of research output of the environmental science researchers at the University of South Africa. Bibliometric and altmetric data were collected via online searches and an online survey was completed by the School of Environmental Sciences during December 2014. The results for online research presence indicate a preference for using free search engines versus fee-based traditional resources. Regarding researcher discoverability via e-profiles, the results indicated a preference for using free websites, with the highest distribution on Linkedln. A higher distribution of research output on free online resources was reported, with a low percentage of researchers participated in self-archiving on social networking tools, in online archives and in repositories, which resulted in a small percentage of accessible research output online. This research suggests that the development of an e-visibility strategy would support and enable academic e-visibility, therefore increasing online research visibility, discoverability and accessibility of the School of Environmental Sciences researchers at University of South Africa.

Keywords: E-visibility, research e-profiles, online presence, online discoverability, online accessibility

\section{Introduction}

Research available online is likely to be cited 4.5 times more than printed (offline) research (Lawrence 2001: 521). Research that is not available and retrievable online is not discoverable and accessible, implying that it is invisible. Research papers need to be more visible for other researchers to utilise them in their research publications. E-visibility embodies the web presence, discoverability and accessibility of research output available online. With the proliferation of online citation resources and academic social networking tools, researchers are increasingly embracing online research practices and becoming part of online research communities. Jeng, He and Jiang (2015: 1) suggested that these online research communities accommodate researchers via e-profiles that create an identifiable online presence. These research e-profiles allow researchers actively to participate in and disseminate research within online research communities, ensuring linked research output is available and accessible online (Arda 2012: 67, Goodier \& Czerniewicz 2012: 1, Lin \& Tsai 2011: 1249, Mangan 2012: 1, Menendez, Angeli \& Menestrina 2012: 56, Redden 2010: 219).

The research for this article forms part of a larger $\mathrm{PhD}$ longitudinal comparative study spanning a two-year period aimed at developing an e-visibility strategy for the researchers of the School of Environmental Sciences (SES) at the University of South Africa (Unisa). The e-visibility study comprised five phases of data collection over six month intervals:

- Phase 1: Data collection to determine the actual e-visibility status (dataset $A$ ) and an online survey (survey $A$ ) to determine the perceived e-visibility status in December 2014;

- $\quad$ Phase 2: Data collection (dataset B) in July 2015;

- Phase 3: Data collection (dataset C) in December 2015;

- Phase 4: Data collection (dataset D) in July 2016; and

- Phase 5: Data collection (dataset E) in December 2016 and an online survey (Survey B) to determine the perceived e-visibility status in April 2017.

This article reports on phase 1 of the research project which focused on determining the perceived e-visibility of the SES researchers (e-visibility survey December 2014) as well as the actual e-visibility recorded via the bibliometric and altmetric data collected in December 2014. On commencement of the study, there was no published South African research

1. Leslie Adriaanse is a doctoral candidate in the Department of Information and Knowledge Management, University of Johannesburg

2. Chris Rensleigh is Professor in Information \& Knowledge Management at the University of Johannesburg 
on correlation between e-visibility and bibliometrics and altmetrics for the environmental sciences. The objectives of the study include determining:

- $\quad$ the e-visibility of the SES researchers focusing on online research presence;

- the discoverability of researchers; and

- the accessibility of research output.

The premise is that e-visibility is enhanced by an increased online research presence; that there will be increased discoverability of researchers through the creation and active maintenance of researcher e-profiles on existing citation resources and academic social networking tools; and that these activities will result in increased accessibility of research output.

\section{Defining e-visibility}

Studies by Bar-llan et al. (2012: 1), Ale-Ebrahim and Salehi (2013: 3) and Norman (2012: 9) supported the culture of an online research presence and encouraged researchers to publish in high impact online journals for increased visibility and to be discoverable and accessible. A number of studies focused on creating research e-profiles to increase the online presence of researchers (Alsagoff 2012: 1, Cann, Dimitriou \& Hooley 2011: 15, Chang 2012: 1, Goodier \& Czerniewicz 2012: 1). A researcher's online presence on the World Wide Web can be defined "as the number of web (co-) mentions of each researcher" and translates "the number of online mentions" the research output of a researcher receives on the web (Chung \& Park 2012: 207). The importance of an online presence as a theme of e-visibility emerges. According to Norman (2012: 4), research should be visible in a suitable format to all possible audiences of online platforms. Research by AleEbrahim et al. (2013: 120) indicated that researchers and their research output must be discoverable. The concept of discoverability translates into the published output of a researcher being easy to find and searchable on online platforms and tools on the web. The theme of discoverability emerges as another e-visibility concept. Research by Norman (2012: 4), Repanovici (2011: 126) and Ale-Ebrahim and Salehi (2013: 3) suggested that the accessibility of publications translates into research output being easily available online to other researchers. This implies that the research is accessible via online repositories which host output for dissemination and archival purposes (Repanovici 2011: 116, Norman 2012: 4) and is retrievable and downloadable for perusal and citation by other researchers (Czerniewicz \& Wiens 2013: 39). The last theme of e-visibility, that of accessibility, emerges. The concept of e-visibility therefore embodies the following themes: the researcher's online presence, research discoverability, and research accessibility. For the purpose of this study, e-visibility can be described as "the online presence, discoverability and accessibility of a researcher and his/her research on the web".

Figure 1 E-visibility in a research community context

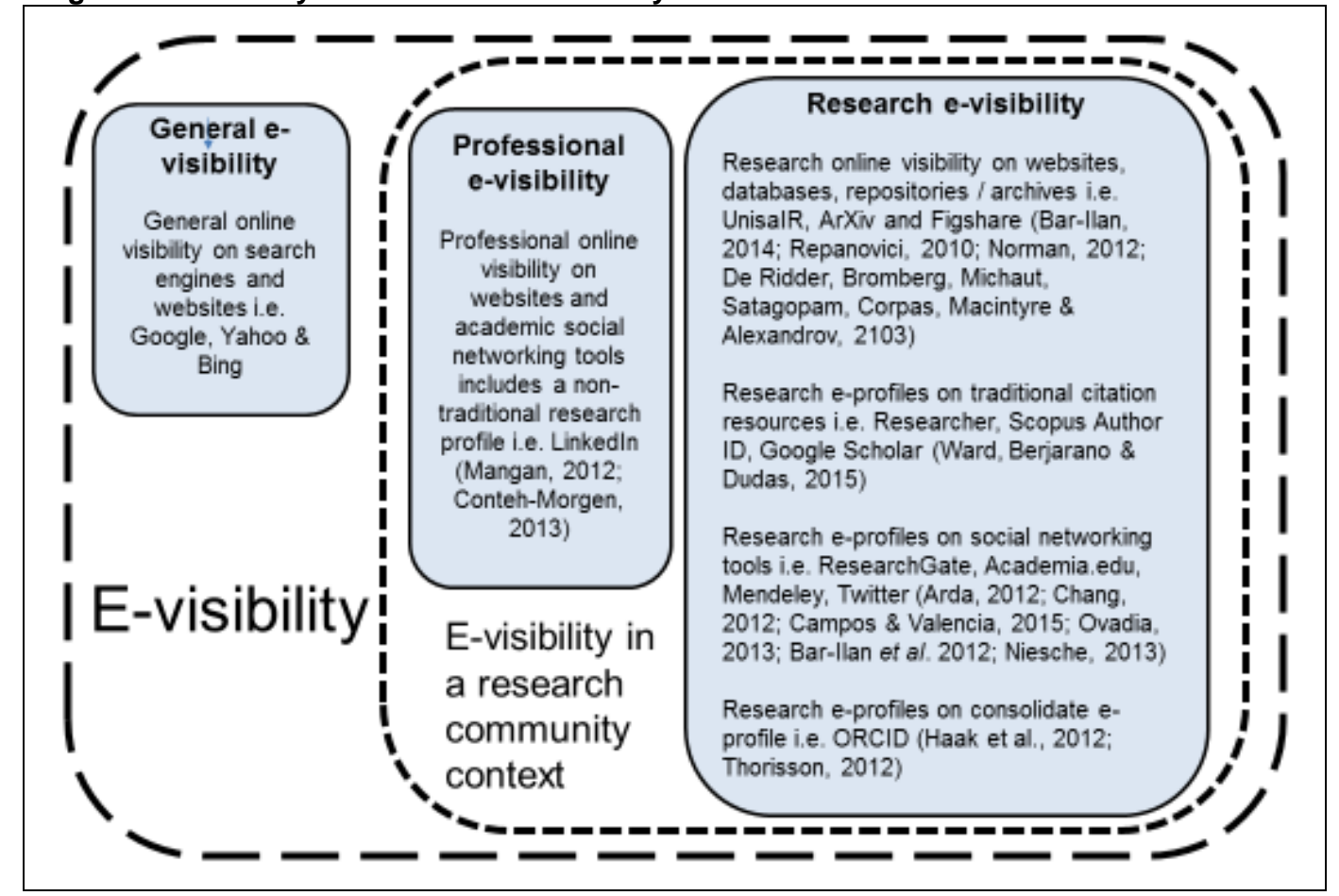


Essentially, embracing e-visibility translates to researchers increasing their online presence with the view to enhancing their online discoverability as researchers via research e-profiles, and enhancing the accessibility of their research output for maximum retrieval possibilities by other researchers. E-visibility empowers researchers to be visible across various online platforms on the internet to enhance their discoverability and accessibility. E-visibility, as interpreted by this study (see Figure 1), creates an opportunity for researchers to share knowledge across various online communities, supporting common ideas for a common purpose - in other words, create a research community. The assumption is that like-minded researchers would network and collaborate to promote e-visibility within a research community. A research community includes a professional online community promoting professional e-visibility, such as Linkedln (Mangan 2012: 2), and academic online communities on social networking tools and websites promoting research e-visibility, such as Academia.edu, ResearchGate, Mendeley, and Twitter (Arda 2012: 72, Bar-Ilan 2014: 217, Campos \& Valencia 2015: 1, Chang 2012: 1, Niesche 2013: 1, Ovadia 2013: 166). Goodier and Czerniewicz (2012: 1) highlighted that researchers start managing their research when they actively start creating and managing their research presence, using online research eprofiles. According to Ward, Bejarano and Dudás (2015: 177), the most acceptable methods of creating an online presence include using an e-profile. Research e-profiles become vehicles that enhance and promote the e-visibility of researchers and their research output.

\section{Research e-profiles}

An e-profile can be described as a "digital representation" of research information about the researcher (Ward, Bejarano \& Dudás 2015: 177). The essential elements necessary for a research e-profile include: electronic representation of the researcher, the researcher's online reputation, and the researcher and/or the research being discoverable and accessible online. The online representation of a researcher and the linked online research is crucial to enhance the online visibility of the researcher. The research e-profile forms part of an online research community, which embraces online research practices and manages the e-profile by updating the biographical and professional information and links to the research. The e-profile is located on an online platform and includes a researcher's biographical and professional research information and affiliation to a research educational institution (Ward, Bejarano \& Dudás 2015: 178). The researcher's online reputation is built and supported by the accurate identification and authentication of the researcher by another researcher and aims to eliminate author ambiguity. A unique identification number (ID) can accurately identify the researcher, distinguishing the researcher from other researchers with the same name in the same discipline (Chang 2012: 1, Piwowar \& Priem 2013: 10). An online profile therefore plays a supportive role and becomes an extension of the researcher's reputation. This implies that the researcher is part of a research community and that the affiliation to a research and/or professional institution forms the foundation of the researcher's professional network (De Ridder et al. 2013: 2). Researchers' membership of a professional research network suggests that network's endorsement of them, their research and their research network. The management of a research e-profile inherently encompasses research reputation management (Ovadia 2014: 166). Online research discoverability and research accessibility translates into the researcher and the research output being discovered, retrieved and downloaded by other researchers from online platforms for their inspection and citation (Czerniewicz \& Wiens 2013: 39). The research e-profile acts as a vehicle to enhance researcher discoverability and research output accessibility.

There are three types of researcher e-profiles: traditional citation e-profiles, academic social networking e-profiles, and professional e-profiles. The traditional citation e-profiles include ResearcherID by Clarivate (previously Thomson Reuters); Scopus Author Profile by Elsevier and Google Scholar Citation Profile (Ward, Bejarano \& Dudás 2015: 179). ORCID is an example of a consolidated research e-profile (Foley \& Kochalko 2012: 319, Mikki et al. 2015: 170). It creates a central registry of unique identifiers for individual researchers, which allows for open and transparent linking mechanisms between various existing research e-profiles such as Google Scholar, ResearchGate, Academia.edu and institutional websites. Publication lists available online via research profiles such as Researcher ID and Scopus can be linked to enhance the research profile. Academic social networking research e-profiles are created on various websites and social networking tools including ResearchGate, Academia.edu, Mendeley, and Linkedln, which is an example of a professional research eprofile (Arda 2012: 72, Bar-llan 2014: 217, Campos \& Valencia 2015: 1, Chang 2012: 1, Niesche 2013: 1, Ovadia 2013: 166).

\section{Research Methodology}

This article reports on the perceived and actual e-visibility of the School of Environmental Sciences (SES) researchers at Unisa in December 2014. The e-visibility study is the first phase of a longitudinal exploratory study (December 2014 to December 2016) aimed at developing an e-visibility strategy for SES researchers. The first set of data collected used a quantitative method focused on collecting data on the perceived e-visibility of the SES researchers with a semi-structured questionnaire in the form of an online survey using SurveyMonkey. Of the seventy-six SES researchers, sixty-two consented 
to participate of which forty-seven responded $(75.81 \%$ response rate). The e-visibility survey allowed for the following content to be collected: online searching to ascertain online presence, discoverability represented by online research eprofiles, accessibility of research output, social networking presence of research, and ascertaining the online traditional and alternative research impact. The e-visibility survey responses were exported into Excel, coded and analysed using SPSS descriptive statistics to determine the perceived e-visibility status of the SES researchers. The data can only be generalised to SES researchers. The second set of data collected was a set of bibliometric and altmetric quantitative data pertaining to SES researchers and their e-visibility and was collected in December 2014 (dataset A). The bibliometric and altmetric data were collected via online searches on the websites selected from existing research literature. The search strategy included using the SES researcher's name as keyword for retrieving and collection of all relevant bibliometric and altmetric data. For the purposes of reporting for this article, e-visibility incorporates the following objectives illustrated in the themes: online research presence, researcher discoverability, and accessibility of research output. These themes will form the reporting categories for e-visibility. The bibliometric and altmetric data extracted per theme included the following:

- Online research presence recorded the following: general web resource tool application; repositories and online archives; social networking tools; academic social networking tools; reference management with social networking capabilities; and traditional citation resources.

- Researcher discoverability recorded the presence of research e-profiles in the following: websites according to traditional profiles (Scopus, Google Scholar, ORCID, ResearcherID); academic social networking tool profiles (Academia.edu, ResearchGate and Mendeley); and professional profiles (Linkedln).

Accessibility of research output recorded the presence of research output on pre-selected websites: Clarivate's (previously Thomson Reuters) Web of Science, Scopus, Google Scholar, ORCID, ResearchGate, Academia.edu, Mendeley, Twitter, Unisa institutional repository (IR), ResearcherID, PLOS ONE, Linkedln, and Altmetric.com.

- Research Impact recorded the bibliometric and altmetric information in the following: traditional citation resources such as researcher name, list of research output, number of publications, citation count, h-index; and, from social networking tools and websites, harvesting attention data such as views, downloads, readers, and reads.

The data were recorded in Excel, coded and analysed using descriptive statistics to determine the actual e-visibility of the SES researchers.

\section{Results and discussions}

The following are the results of the study, including discussions around the perceived e-visibility (results from survey A) and actual e-visibility (dataset $A$ ) of the SES researchers.

\subsection{Biographical profile of SES researchers}

The biographical information from the survey reported the largest percentage (53\%) of respondents fall in the 20-30 age group, with the youngest respondent being 24 years old and the oldest 69 years old. Taking the actual research level into consideration, there was an even distribution of under 40 and over 40 -year-olds. Research by Jamali, Russell and Nicholas (2014: 607) reported similar results where the average age group of the respondents was 36 to 45 years for researchers participating in a survey regarding the usage of online social networking tools. The results suggest that the majority of the forty-seven respondents (forty-three; $91 \%$ ) hold a postgraduate qualification, with $39 \%$ (eighteen) holding a Master's degrees, 33\% (fifteen) a doctorate, 22\% (ten) honours degrees, $4 \%$ (two) a diploma and $2 \%$ (one) a bachelor or equivalent degree. The results show that $40 \%$ (seventeen) were employed at the level of lecturer followed by nine junior lecturers $(21 \%)$, six senior lecturers (14\%), six professors (14\%), three managers $(7 \%)$ and two associate professor $(5 \%)$. Regarding research levels, the respondents described themselves as either emerging researchers $(69 \%)$ or established researchers $(24 \%)$, which included research categories as defined by the National Research Foundation (NRF). In addition, two people indicated a NRF Y2 rating and one a C2 rating. The actual research level indicated that there was a larger distribution of researchers within the emerging research category than in the established category. The total amount of research output for the SES researchers for December 2014 is 662 items. The majority $545(82 \%)$ of the research output was published by those researchers over 40 years of age and $482(73 \%)$ research outputs were published by established researchers.

The results indicate that a large percentage of respondents (74\%) have published journal articles in accredited journals, whereas $47 \%$ have published in non-accredited journals. The results also show that $43 \%$ have presented papers at accredited conferences and $53 \%$ at non-accredited conferences. The results of the publication of books indicate that $21 \%$ have accredited books to their names, compared to $77 \%$ with non-accredited books; $55 \%$ have published chapters in accredited books and $72 \%$ in non-accredited books. The average publication count for researchers are journal articles: 3.7 ; conference papers: 1.3 ; books: 0.7 ; and chapters in books: 0.9 . 


\subsection{Online presence}

The perceived and actual e-visibility of researchers can be expressed using the results obtained from the e-visibility survey (survey A) and the bibliometric and altmetric data collected in December 2014 using the three categories: online presence, discoverability via research e-profiles, and the accessibility of research output available online. The perceived and actual online presence of the SES researchers are illustrated in Figure 2.

Figure 2 Online distribution of online presence of the SES researchers

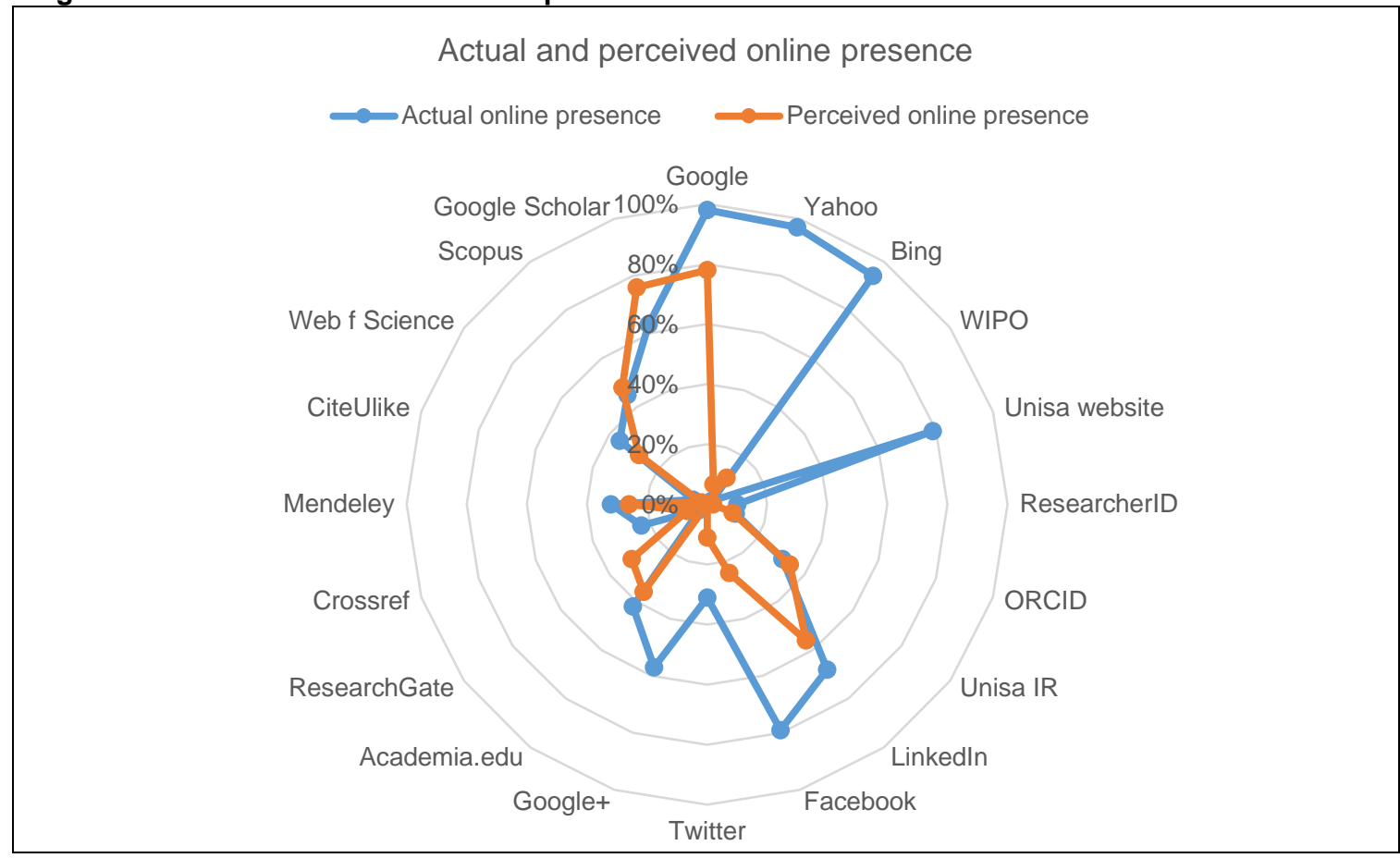

The perceived online presence indicates a high distribution of use of free search engines and social media tools to assert online research presence. These search engines and tools included Google (78\%), Google Scholar (76\%), Linkedln $(56 \%)$, ResearchGate $(36 \%)$ and Academia.edu (31\%). The results further indicate lower percentages in usage of feebased traditional research databases in order to assert online presence and provide information about research output. These databases included Scopus (48\%) and Web of Science $(28 \%)$. The survey indicated that $4 \%$ of the respondents used no websites and tools to ascertain their online research presence. The actual online presence (obtained from dataset A) reported a high percentage of representation on general free search engines with Google (98\%) followed by Yahoo (97\%) and Bing (94\%). The Unisa institutional website showed $79 \%$ of the SES researchers indicating their Unisa affiliation online. The social networking tools Facebook (79\%), Linkedln (68\%) and Google+ $(57 \%)$ reported high distributions for online presence; there were low distributions in Academia.edu (36\%) and ResearchGate (31\%). The results indicate a lower percentage of presence on the fee-based web resources and traditional research databases Scopus (45\%) and Web of Science $(36 \%)$. The results further indicate that $62 \%$ of respondents do not use reference management tools with social networking capabilities, 2\% using Mendeley, 6\% Crossref and 2\% CiteuLike.

Regarding the online research presence of the SES researchers, the two sets of results (survey $A$ and dataset $A$ ) suggest the majority of the SES respondents have a high distribution of actual and perceived online presence on free websites and social networking tools with a lower distribution of online presence on the fee-based web resources. It is evident that there is a preference towards using free search engines and web resources. Similarly, research by Hemminger et al. (2007: 2214) indicated that the majority of researchers (53\%) participating in a survey used Google Scholar for initial searching for research purposes. Research by Niu et al. (2010: 876) stated that most researchers are familiar with search engines and express a preference for conducting meta-searching on free search engines. This statement supports the findings of the study as the majority of the respondents use free search engines and tools.

\subsection{Discoverability}

The perceived and actual discoverability of SES researchers are illustrated in Figure 3. Dataset A and survey A indicated, respectively, that $15 \%$ and $7 \%$ of the participating SES researchers had no research profiles. The perceived researcher discoverability obtained from survey $\mathrm{A}$ indicated that the largest percentage of respondents $(65 \%)$ used the professional social networking tool, Linkedln, to create or register their research e-profiles followed by academic social networking tools 
ResearchGate (44\%) and Academia.edu (33\%). In addition, the respondents indicated they have research e-profiles on Scopus (27\%), Google Scholar (26\%), Mendeley (18\%), ORCID (9\%) and ResearcherID (2\%). The actual discoverability via research e-profiles obtained from dataset A reported the largest percentage of e-profiles on Linkedln (83\%), followed by ResearchGate and Scopus, both with $57 \%$. Academia.edu reported 49\%, with Google Scholar and Mendeley both on $34 \%$, and ORCID and ResearcherID both on $9 \%$.

Figure 3 Actual and perceived discoverability via research e-profiles for SES researchers



Although Linkedln is not considered an academic social networking tool (since no research output was linked directly to the Linkedln profile), it functions in a similar way to a research profile. Linkedln provides a professional e-profile containing the professional information of a researcher for employment purposes. The presence of research e-profiles on Scopus and ResearchGate (43.6\%) indicates an even distribution of research e-profiles on social networking tools and traditional citation resources. Research by Menendez, Angeli and Menestrina (2012: 56) and Jamali, Russell and Nicholas (2014: 607) suggested similar results, with a high distribution of e-profiles on free professional websites (Linkedln) and social networking tools (ResearchGate and Academica.edu), whereas research by Mikki et al. (2015: 170) indicated the highest distribution of e-profiles to be on ResearchGate. The actual discoverability results indicated that $23 \%$ of the respondents had only one research profile of which the majority $(71 \%)$ were on Linkedln, followed by ResearchGate and Mendeley. The rest had a combination of two or more profiles across the various websites and databases identified as focusing on research profiles. The largest overlap of research e-profiles was between Scopus and ResearchGate with twenty respondents, followed by Scopus and Academic.edu with fifteen each. ResearchGate, Academia.edu, Google Scholar and Scopus had equal overlap with fourteen research e-profiles. The research by Mikki et al. (2015: 8) reported an overlap of research profiles of more than $50 \%$ between ResearchGate and Academia.edu. In contrast, the current study indicates an overlap of less than $50 \%$ for ResearchGate and Academia.edu.

Regarding the online discoverability, the perceived online discoverability suggests a preference towards using free professional (Linkedln) and social networking (ResearchGate and Academia.edu) e-profiles rather than the traditional research websites and citation resources (Web of Science, Scopus, Google Scholar and ORCID). The actual discoverability indicates an even distribution of research e-profiles on free websites (Linkedln) and social networking tools (ResearchGate) and traditional citation resources (Scopus). This implies a high online discoverability on free professional and social networking tools, but lower online discoverability on traditional resources.

\subsection{Accessibility}

The investigation into the perceived accessibility of the SES researchers' output reported on where the research output was linked to online archives and repositories (institutional and subject repositories); the percentage of total research; and the types of scholarly publications archived on websites, databases and social networking tools. The Unisa IR reported $34 \%$ uploading research output and $2 \%$ uploaded to subject archives. The results further indicate that $63 \%$ do not upload their research onto the institutional repository or a subject archives. The implication of not having uploaded and/or archived to 
the institutional repository is that the research is not necessarily accessible to other researchers and thus less discoverable. The perceived accessibility for linking research output online is illustrated in Figure 4.

Figure 4 Perceived accessibility via research e-profiles for SES researchers

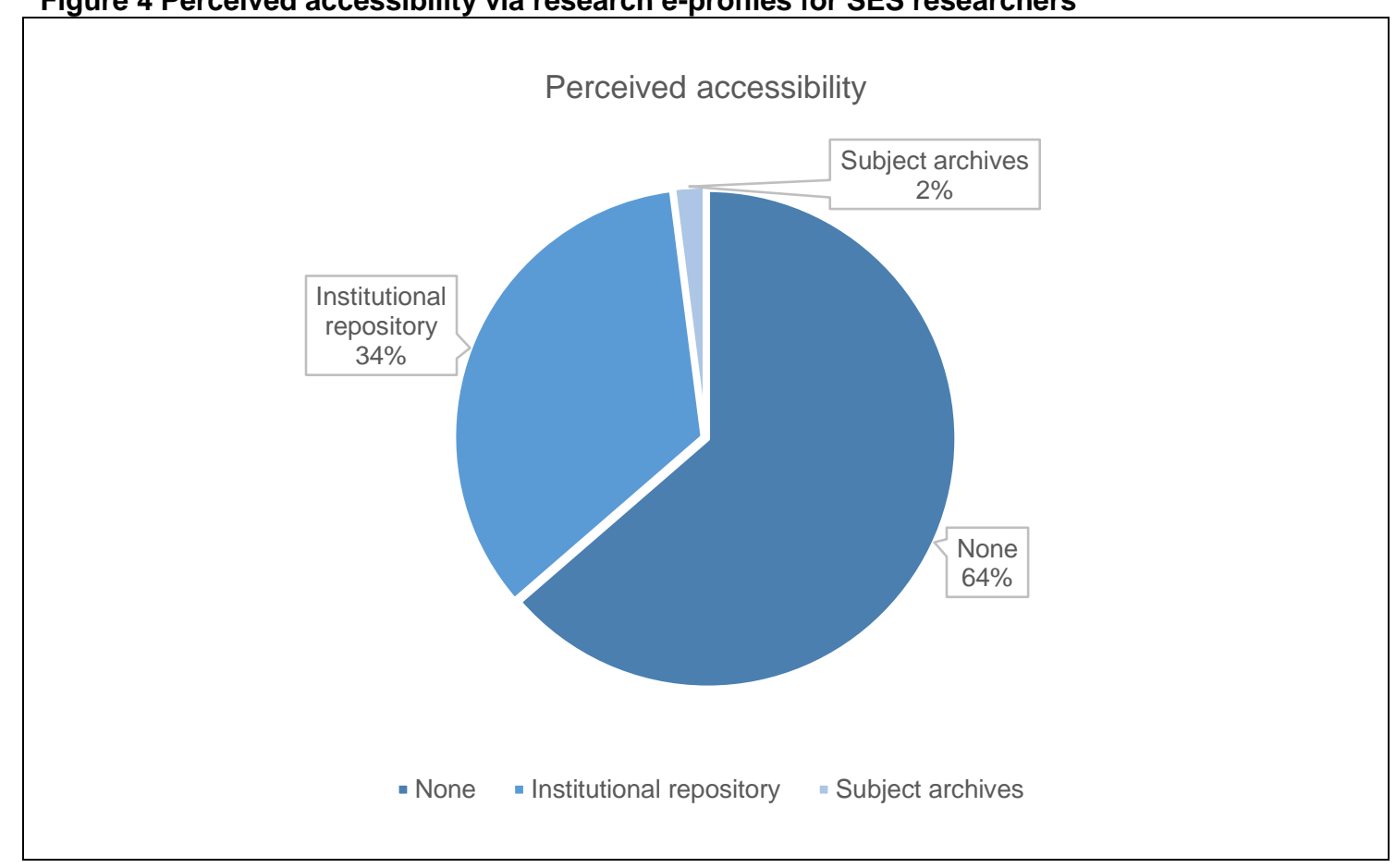

The survey results indicate a preference for uploading journal articles (22\%), followed by conference papers (14\%), chapters in books (12\%), slide presentations (5\%) and pictures, photos or figures (3\%). The survey results also indicate that $59 \%$ of the respondents upload no research output. Only $5 \%$ indicated linking all of their research output to the institutional repository or subject archives (see Figure 5).

\section{Figure 5 Research output for SES researchers uploaded}

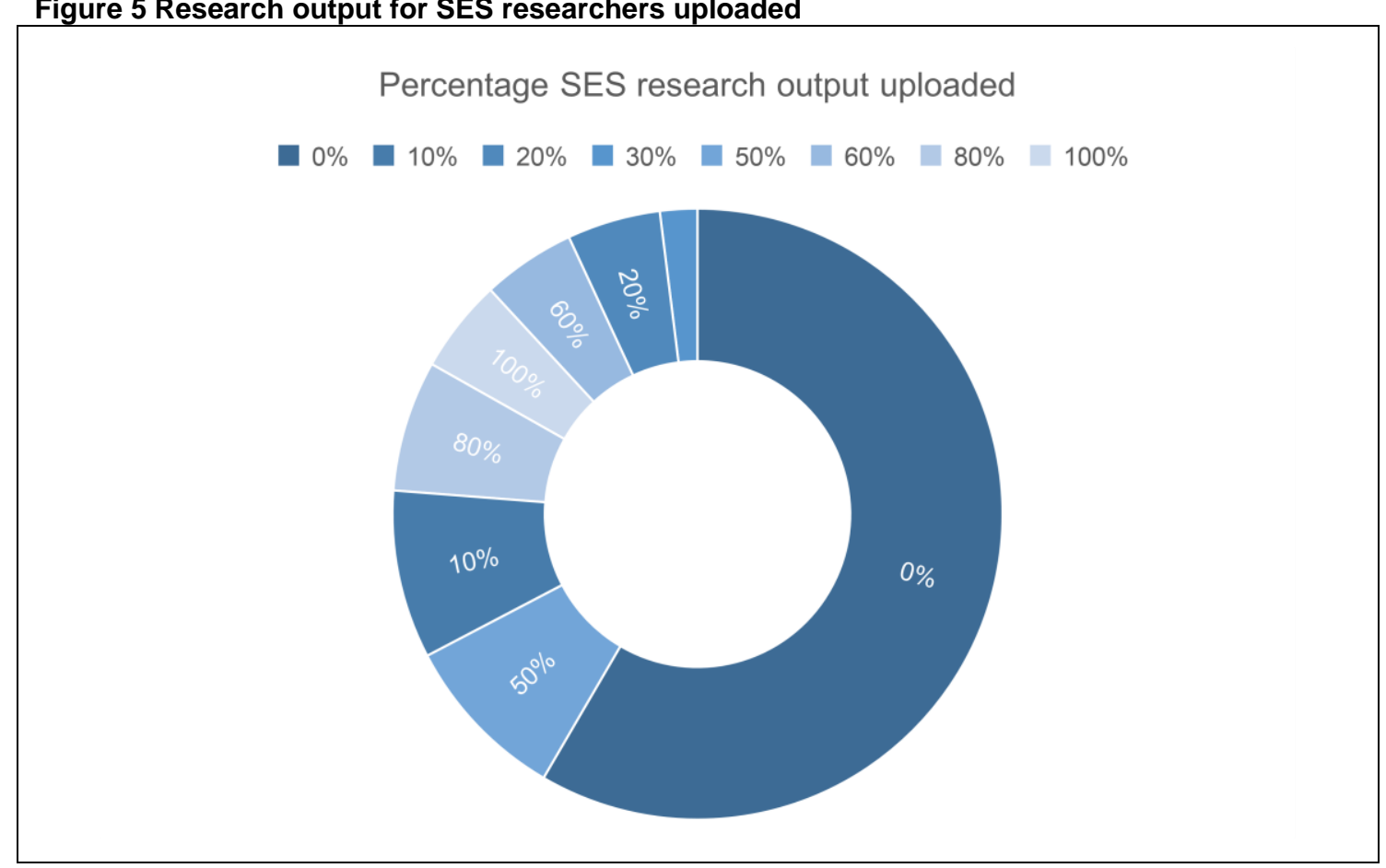

The actual accessibility shows that the number of research publications for SES researchers totals 662 . The results indicate that $32 \%$ had no research output represented in December 2014. The largest distribution of accessible research output was on Google Scholar (322 items; 30\%), followed by ResearchGate (270 items; 25\%). Scopus contained 270 
(16\%), Web of Science $128(12 \%)$ and seventy-six items (7\%) on both the Unisa IR and Academia.edu. Mendeley contained only eight items, ORCID seven items, and there were three items on ResearcherID. LinkedIn and PLOS ONE both contained no items. Figure 6 illustrates the actual online accessibility on the websites, databases and social networking tools.

Figure 6 Actual accessibility of SES researchers

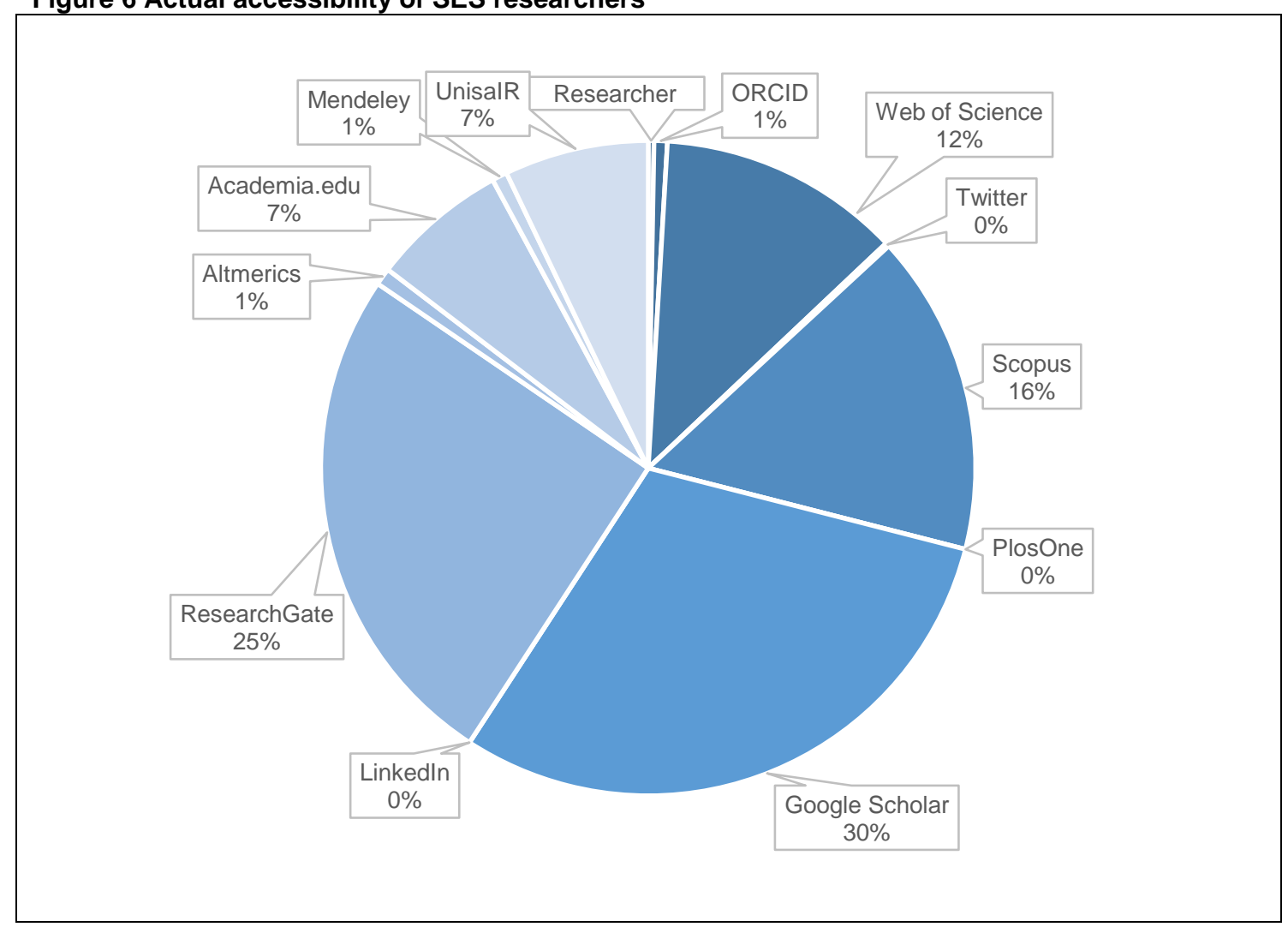

Figure 7 Websites, search engines and databases used for traditional impact

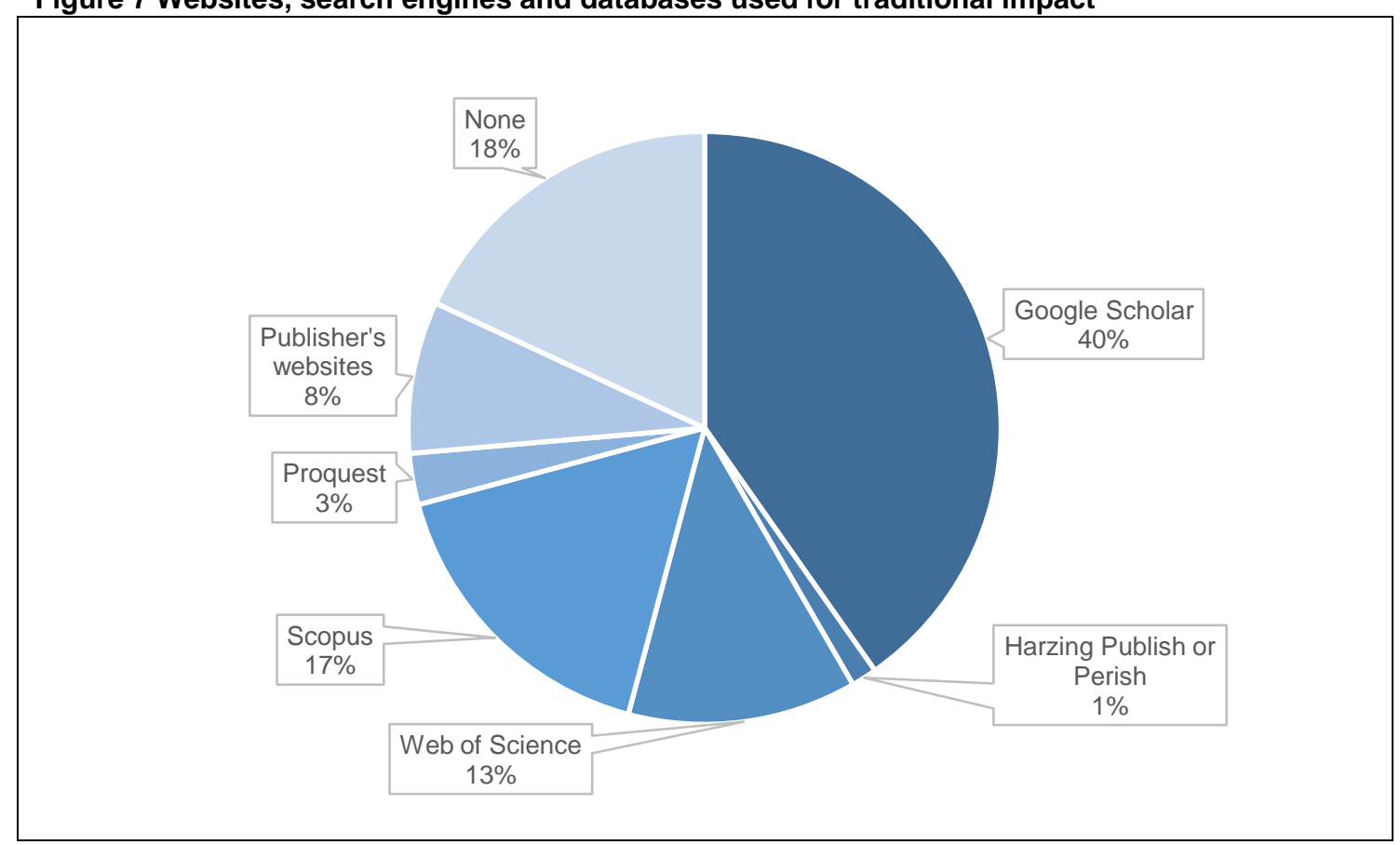

The implication of almost two-thirds of the respondents not uploading to the institutional repository is that research output is not accessible and less discoverable to online audiences. In addition, low percentages of linking to institutional repositories means low visibility on Google Scholar and academic search engines. Similar results of low participation rates of academics self-archiving in repositories and online archives were reported by Jantz and Wilson (2008: 186), Cullen and Chawner (2011: 468), Bankier and Perciali (2008: 21) and Lercher (2008: 408). 


\subsection{Online research impact}

The perceived online traditional research impact results, as illustrated in Figure 7, showed that $40 \%$ of respondents use Google Scholar followed by Scopus (17\%) and Web of Science (13\%). The alternative research impact results indicate that $54 \%$ of respondents do not use websites, search engines and databases to ascertain their alternative impact, with $24 \%$ utilising Academia.edu and 20\% ResearchGate, as illustrated in Figure 8.

Figure 8 Websites, search engines and databases used to search for alternative metric impact

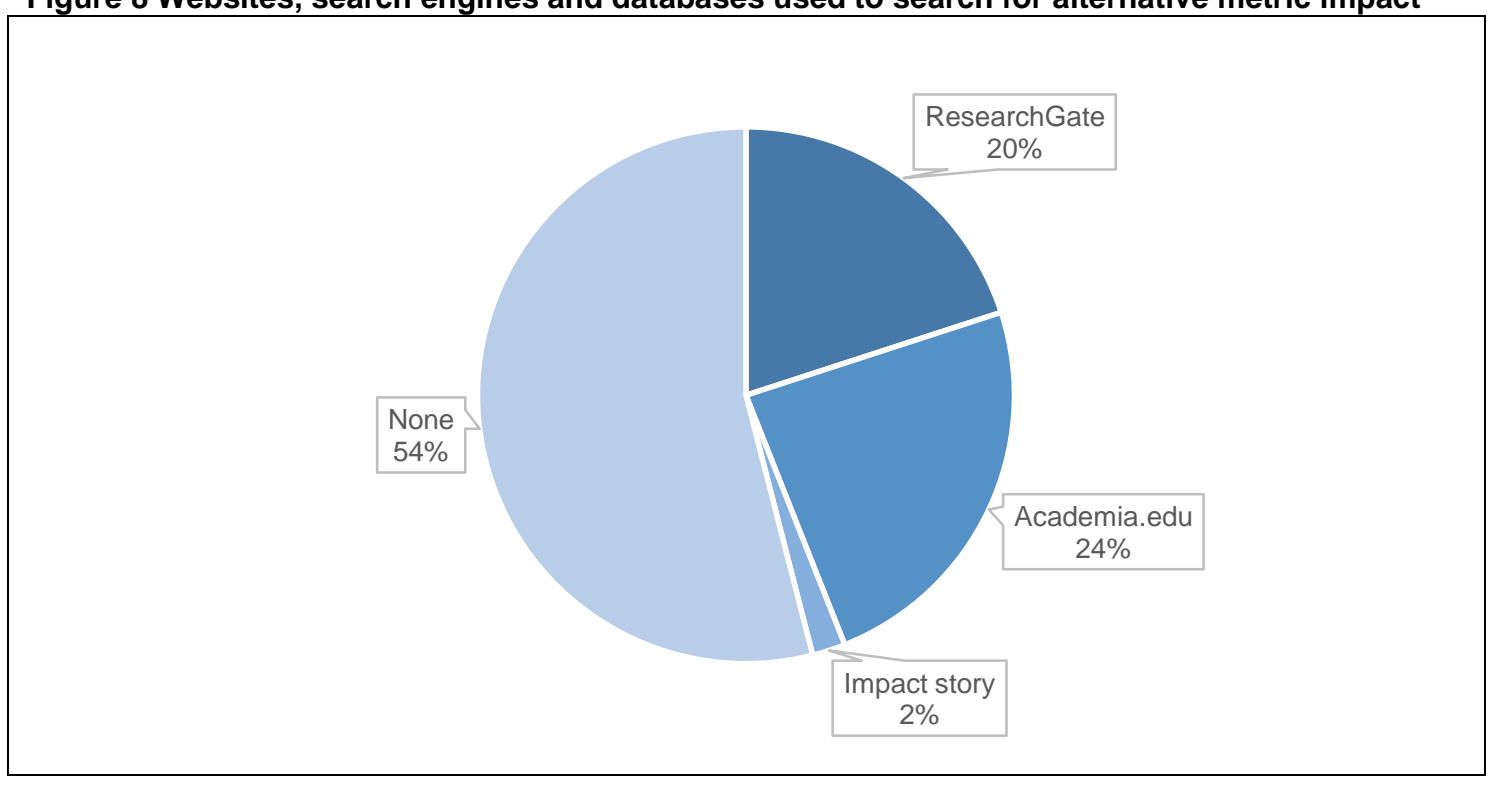

The results for dataset $A$ include the bibliometrics sourced from Web of Science, Scopus and Google Scholar, as indicated in Table 1. The results indicate $35 \%$ of the respondents have research output on Web of Science. There are a total of 128 research outputs with an average of 5.8 research outputs per researcher. The total citations on Web of Science is 685 , with an average of 31.1 for the participating SES researchers and an average of eleven citations for the research output on Web of Science. The results indicate $40 \%$ of SES researchers have research output on Scopus. The total number of research outputs for SES researchers on Scopus was 270, with an average of 7.7 research outputs per researcher. The SES researchers have a total of 817 citations on Scopus, with an average of 32.7 for the entire group participating and an average of 13.2 for the SES researcher with research output on Scopus. The results indicate $60 \%$ of SES researchers have research output on Google Scholar. The total number of research outputs for SES researchers on Google Scholar is 322 , with an average of 14.6 research outputs per researcher. The SES researchers have a total of 1,308 citations on Google Scholar, with an average of 35.4 for the entire group participating and an average of 21.1 for the SES researchers with research output on Google Scholar.

Table 1 Results from traditional bibliometrics

\begin{tabular}{lc|c|c}
\hline \multirow{2}{*}{ Citation metric information } & \multicolumn{3}{c}{ Traditional citation resource } \\
\cline { 2 - 4 } & Web of Science & Scopus & Google Scholar \\
\hline Number of SES researchers & $22(35 \%)$ & $25(40 \%)$ & $37(60 \%)$ \\
Total number of publications & 128 & 270 & 322 \\
Average publication per SES researchers & 5.8 & 7.7 & 14.6 \\
Total number of citations & 685 & 817 & 1308 \\
Average citations per SES researchers & 11.0 & 13.2 & 21.1 \\
Average citations per SES researcher publishing on Web of Science & 31.1 & 32.7 & 35.4 \\
\hline
\end{tabular}

The results for the alternative impact was sourced from websites and social networking tools as indicated in Table 2 . The actual alternative impact results include the altmetrics sourced from specific identified social networking tools. The results show that twenty-five of SES researchers have research output on ResearchGate. The total number of research outputs for SES researchers was 270, with an average of 12.3 research outputs per researcher. Eighteen SES researchers have research output on Academia.edu. The total number of research outputs for SES researchers on Academia.edu was seventy-two, with an average of 3.7 research outputs per researcher. Sixteen SES researchers have research output on Mendeley, while nineteen have research output on Unisa IR. 
Number of SES researchers

Total number of publications

SES researchers with publications linked to profile / website platform

Average publication per SES researcher

Total number of views

Total number of downloads

Total number of readers

Total number of tweets

Total number of AM Score

Total AM Score for SES Researchers

\begin{tabular}{c|c|c|c|c|c|c}
\multicolumn{7}{c}{ Alternative citation resources } \\
\hline Academia.edu & ResearchGate & PLOS ONE & Mendeley & Unisa IR & Twitter & Altmetric.com \\
\hline 18 & 25 & 0 & 16 & 19 & 21 & 6 \\
72 & 270 & 0 & 8 & 91 & 11 & 9 \\
10 & 22 & 0 & 2 & 19 & 3 & 6 \\
3.7 & 12.3 & 0 & 0.6 & 5.4 & 3.7 & 1.7 \\
3923 & 9209 & 0 & - & 24901 & - & - \\
- & 2332 & 0 & - & - & - & - \\
- & - & - & 27 & - & - & 145 \\
- & - & - & - & - & 21 & 21 \\
- & - & - & - & - & - & 45 \\
- & - & - & - & - & - & 27 \\
\hline
\end{tabular}

Research by Harzing and van der Wal (2007: 1) indicated that Google Scholar allows for the searching of freelyavailable citation information for citation analysis and adds to the democratisation of citation analysis. Yet, according to Grey et al. (2012: 10) and Aguillo (2012: 350), Google Scholar should not be used independently for citation analysis, but rather used to complement the existing traditional citation resources, Web of Science and Scopus. The traditional research impact and performance information of the researcher ( $\mathrm{h}$-index, total citation count and average citations) can be ascertained from traditional research profiles such as the ResearcherID, Scopus Author and Google Scholar profiles. With only $35 \%$ of SES researchers maintaining Google Scholar profiles, it is implied that only one-third can gauge their bibliometric performance on Google Scholar using the citation analysis functionality. Only $10 \%$ of SES researchers have ResearcherID profiles; likewise, only $10 \%$ of SES researchers can accurately gauge their traditional impact from bibliometrics from Web of Science.

With reference to establishing alternative research impact, the survey results indicate that $54 \%$ of respondents do not use websites, search engines and databases to search for their alternative impact. The results show that Academia.edu (24\%) and ResearchGate (20\%) are being utilised for sourcing alternative research impact. Dataset A reports that $36 \%$ of research output is located on ResearchGate, followed by Unisa IR (31\%), Twitter (18\%), Academia.edu (16\%), Altmetric.com (10\%) and Mendeley (3\%). The possible explanation for the majority of researchers not utilising the various existing websites and social networking tools to determine their alternative citation impact could be that the researchers are not familiar with the concept 'altmetrics' and do not understand the value of altmetrics for research evaluation in the higher education environment. The development of an e-visibility strategy for the SES researchers would provide awareness of the benefits of enhanced research e-visibility, which translates to having an increased online presence, being more discoverable as a researcher, and having one's research output accessible by creating and maintaining research e-profiles on traditional citation resources, academic social networking tools and consolidated e-profiles. An e-visibility strategy would encourage the SES researchers to embrace online research tools and research communities to enhance their e-visibility.

\section{Conclusions and Recommendations}

The objective of this study was to report on the e-visibility of the environmental science researchers at the University of South Africa with specific focus on the e-visibility themes: online presence, researcher discoverability and accessibility of research output of SES researchers. Regarding the online research presence of the SES researchers, there was a preference for using free search engines and web resources (Google, Google Scholar, Bing and Yahoo) rather than feebased web resources (Web of Science and Scopus), implying a high online presence on free search engines and web resources and a low online presence on fee-based web resources. With regards to researcher online discoverability, actual discoverability suggests an even distribution of researcher e-profiles on free websites, social networking tools and traditional citation resources. The perceived online discoverability indicates a preference for using free professional (Linkedln) and social networking (ResearchGate and Academica.edu) e-profiles above the traditional research websites and citation resources (Web of Science, Scopus, Google Scholar and ORCID), implying high online discoverability on free professional and social networking tools but lower online discoverability on traditional profiles. Concerning the online accessibility of the research output of the SES researchers, the majority of research output was located online on free web resources (Google Scholar) and social networking tools (ResearchGate). The survey results indicate a low percentage of respondents archiving their total research output and the majority of respondents indicated a low percentage of archiving of their research on the institutional repository or subject archives. The implication of almost two thirds of the respondents not having uploaded and/or archived on the institutional repository is that the research output is not accessible and thus less discoverable to online audiences. 
The survey results indicated a preference for using free rather than fee-based citation resources to ascertain traditional research impact, with $40 \%$ of respondents preferring to use Google Scholar to Web of Science and Scopus. The actual evisibility status indicated the majority of the research output was located on Google Scholar (60\%). Regarding alternative impact, the survey results reported that the majority of respondents $(54 \%)$ do not use websites, search engines and databases to search for their alternative citation impact. The academic social networking tools Academia.edu (24\%) and ResearchGate (20\%) were the most used in ascertaining alterative research impact, suggesting a high usage of free academic social networking tools to ascertain alternative research impact. Regarding the possible resources for sourcing altmetric information on the research output of participating SES researchers, results for dataset $A$, report a higher distribution of research output to be located on ResearchGate (36\%).

Research e-visibility in essence embodies online presence on the web, discoverability via research e-profiles and accessibility of research output available online. Ideally, high percentages of online presence, high percentages of researcher discoverability, and high percentages of accessibility of research output translates to high levels of research evisibility. Given the results obtained from the e-visibility survey and the bibliometric and altmetric data results collected in December 2014, the SES researchers have a high level of e-visibility on free search engines and web resources and on social networking tools and a low e-visibility on fee-based web resources and databases.

\section{References}

Aguillo, I.F. 2012. Is Google Scholar useful for bibliometrics? A webometric analysis. Scientometrics, 91: 343-351.

Ale-Ebrahim, N. and Salehi, H. 2013. Maximize visibility: a way to increase citation frequency. University of Malyasia High Impact Research, 1-3. [Online]. http://works.bepress.com/aleebrahim/77/ (10 August 2015).

Ale-Ebrahim, N., Salehi, H., Embi, M.A., Gholizadeh, H., Motahar, S.M. and Ordi, A. 2013. Effective strategies for increasing citation frequency. International Educational Studies, 6(11): 93-99. [Online]. http://papers.ssrn.com/sol3/Papers.cfm?abstract_id=2344585 (10 August 2015).

Alsagoff, Z.A. 2012. Using social media for research. [Online]. http://www.slideshare.net/zaid/using-social-media-forresearch-14033970?from_search=1 (10 December 2013).

Arda, Z. 2012. Academicians on online social networks: visibility of academic research and amplification of audience. Estudios sobre el mensaje periodístico, 18: 67-75. [Online]. http://dialnet.unirioja.es/servlet/articulo?codigo=4213526 (10 August 2015).

Bankier, J.G. and Perciali, I. 2008. The institutional repository rediscovered: what can a university do for open access publishing? Serials Review, 34(1): 21-26. [Online]. http://www.sciencedirect.com/science/article/pii/S0098791307001517 (27 November 2013).

Bar-Ilan, J. 2014. Astrophysics publications on arXiv, Scopus and Mendeley: a case study. Scientometrics, 100: $217-225$. [Online]. http://link.springer.com/article/10.1007/s11192-013-1215-1 (07 August 2016).

Bar-Ilan, J., Haustein, S., Peters, J., Shema, H. and Terliesner, J. 2012. Beyond citations: scholar's visibility on the social web. Proceedings of the $17^{\text {th }}$ International Conference on Science and Technology Indicators. 5-8 September. Montreal, Canada. [Online]. http://arxiv.org/abs/1205.5611 (12 December 2013).

Campos, F. and Valencia, A. 2015. Managing academic profiles on scientific social networks. New Contributions in Information Systems and Technologies, 353: 265-273. [Online]. http://link.springer.com/chapter/10.1007/978-3-31916486-1_27 (10 August 2015).

Cann, A., Dimitriou, K. and Hooley, T. 2011. Social media: a guide for researchers. London: Research information network. [Online]. http://derby.openrepository.com/derby/handle/10545/196715 (14 August 2016).

Chang, N. 2012. Creating a strong online presence as an academic. [Online], Available: http://www.theihs.org/academic/2012/06/07/creating-a-strong-online-presence-as-an-academic-part-2-control-yourbrand/ (10 August 2015).

Chung, C. and Park, H. 2012. Web visibility of scholars in media and communication journals. Scientometrics, 93(1): 207215. [Online]. http://www.akademiai.com/doi/abs/10.1007/s11192-012-0707-8 (14 February 2015).

Cullen, R. and Chawner, B. 2011. Institutional repositories, open access, and scholarly communication: a study of conflicting paradigms. The Journal of Academic Librarianship, 37(6): 460-470.

Czerniewicz, L. and Wiens, K. 2013. The online visibility of South African knowledge: searching for poverty alleviation: Building the information society. The African Journal of Information and Communication, August: 30-41. [Online]. http://reference.sabinet.co.za/sa_epublication_article/afjic_n13_a4 (10 August 2015).

De Ridder, J., Bromberg, Y., Michaut, M., Satagopam, V.P., Corpas, M., Macintyre, G. and Alexandrov, T. 2013. The Young PI Buzz: learning from the organisers of the junior principal investigator meeting at ISMB-ECCB 2013. PLoS Computational Biology, 9(11): e1003350.

Foley, M. and Kochalko, D. 2012. Open researcher and contributor identification (ORCID). Proceedings of the Charleston Library Conference. 2-5 November 2011. West Lafayette: Purdue University, 320-323. [Online]. http://docs.lib.purdue.edu/charleston/2010/OutofBox/1/ (28 July 2016).

Harzing, A. and van der Wal, R. 2007. Google Scholar: the democratization of citation analysis? Ethics in Science and Environmental Politics, 8: 61-73. 
Hemminger, B.M., Lu, D., Vaughn, K.T.L. and Adams, S. 2007. Information seeking behavior of academic scientists. Journal of the American Society for Information Science and Technology, 58(14): 2205-2225.

Goodier, S. and Czerniewicz, L. 2012. Academics' online presence: a four-step guide to taking control of your visibility. [Online]. http://openuct.uct.ac.za/sites/default/files/Online Visibility Guidelines.pdf (10 August 2015).

Grey, J.E., Hamilton, M.C., Hauser, A., Janz, M.M., Peters, J.P. and Taggart, F. 2012. Scholarish: Google Scholar and its value to the sciences. Science and Technology Librarianship, summer 2012: 1-10.

Jamali, H.R., Russell, B. and Nicholas, D. 2014. Do online communities support research collaboration? Aslib Journal of Information Management, 66(6): 603-622. [Online]. http://www.emeraldinsight.com/doi/abs/10.1108/AJIM-08-20130072 (19 August 2016).

Jantz, R.C. and Wilson, M.C. 2008. Institutional repositories: faculty deposits, marketing, and the reform of scholarly communication. The Journal of Academic Librarianship, 34(3): 186-195.

Jeng, W., He, D. and Jiang, J. 2015. User participation in an academic social networking service: a survey of open group users on Mendeley. Journal of the Association for Information Science and Technology, 66(5): 890-904. DOI:10.1002/asi.23225.

Lawrence, S. 2001. Free online availability substantially increases a paper's impact. Nature, 411(6837): 521-521. [Online]. http://www.nature.com/nature/journal/v411/n6837/full/411521a0.html (10 August 2015).

Lercher, A. 2008. A Survey of attitudes about digital repositories among faculty at Louisiana State University at Baton Rouge. The Journal of Academic Librarianship, 34(5): 408-415. [Online]. http://www.sciencedirect.com/science/article/pii/S009913330800102X (27 November 2013).

Lin, C.C. and Tsai, C.C. 2011. Applying social bookmarking to collective information searching (CIS): an analysis of behavioral pattern and peer interaction for co-exploring quality online resources. Computers in Human Behavior, 27(3): 1249-1257.

Mangan, K. 2012. Social networks for academics proliferate, despite some doubts. Chronicle of Higher Education, 29 April. [Online]. http://chronicle.com/article/Social-Networks-for-Academics/131726/ (27 November 2013).

Menendez, M., Angeli, A. and Menestrina, Z. 2012. Exploring the virtual space of academia. In From research to practice in the design of cooperative systems: results and open challenges. J. Dugdale, C. Masclet, M.A. Grasso, J.F. Boujut, and P. Hassanaly. Eds. Springer: London. 49-63. [Online]. http://link.springer.com/chapter/10.1007/978-1-44714093-1_4 (25 May 2016).

Mikki, S., Zygmuntowska, M., Gjesdal, Ø.L. and Al Ruwehy, H.A. 2015. Digital presence of Norwegian scholars on academic network sites: where and who are they? PLOS ONE, 10(11): e0142709.

Niesche, C. 2013. Who are you online? Creating a web presence for academics: how to make the most of your online profiles. [Online]. http://intheblack.com/articles/2013/06/26/who-are-you-online-creating-a-web-presence-foracademics (10 August 2015).

Niu, X., Hemminger, B.M., Lown, C., Adams, C., Level, A., McLure, M., Powers, A., Tennant, M.R. et al. 2010. National study of information seeking behavior of academic researchers in the United States. Journal of the American Society for Information Science and Technology, 61(5): 869-890.

Norman, E. 2012. Maximizing journal article citation online: readers, robots, and research visibility. Politics \& Policy, 40(1): 1-12. [Online]. http://onlinelibrary.wiley.com/doi/10.1111/j.1747-1346.2011.00342.x/full (18 June 2015).

Ovadia, S. 2013. When social media meets scholarly publishing. Behavioral \& Social Sciences Librarian, 32(3): 194-198.

Ovadia, S. 2014. ResearchGate and Academia.edu: academic social networks. Behavioral \& Social Sciences Librarian, 33(3): 165-169.

Piwowar, H. and Priem, J. 2013. The power of altmetrics on a CV. Bulletin of the American Society for Information Science and Technology, 39(4): 10-13.

Redden, C.S. 2010. Social bookmarking in academic libraries: trends and applications. The Journal of Academic Librarianship, 36(3): 219-227.

Repanovici, A. 2011. Measuring the visibility of the university's scientific production through scientometric methods. Performance Measurement and Metrics, 12(2): 106-117.

Ward, J., Bejarano, W. and Dudás, A. 2015. Scholarly social media profiles and libraries: a review. LIBER Quarterly, 22(4): 174-204. [Online]. http://liber.library.uu.nl/index.php/lq/article/view/9958/10504 (12 May 2015). 